\title{
Prevalence of Dental Fluorosis in Saudi Arabia: A Meta-Analysis
}

\author{
Freah Alshammary1 ${ }^{\circledR}$, Ammar Ahmed Siddiqui1 ${ }^{\circledR}$, Abdulmjeed Sadoon Al-Enizy² ${ }^{\circledR}$, Saleh Ali Saleh \\ Almalaq ${ }^{1}$, Junaid Amin ${ }^{3}$, Hassaan Anwer Rathore ${ }^{4}$, Fatma Ayyad Alshammary ${ }^{2}$, Mohammad \\ Khursheed Alam ${ }^{5}$
}

\begin{abstract}
${ }^{1}$ Department of Preventive Dental Sciences, College of Dentistry, University of Hail, Hail, Kingdom of Saudi Arabia. ${ }^{2}$ College of Dentistry, University of Hail, Hail, Kingdom of Saudi Arabia.

${ }^{3}$ College of Applied Medical Sciences, University of Hail, Hail, Kingdom of Saudi Arabia.

${ }^{4}$ College of Pharmacy, University of Hail, Hail, Kingdom of Saudi Arabia.

${ }^{5}$ Orthodontic Department, College of Dentistry, Jouf University, Sakaka, Kingdom of Saudi Arabia.
\end{abstract}

Author to whom correspondence should be addressed: Ammar Ahmed Siddiqui, Department of Preventive Dental Sciences, College of Dentistry, University of Hail, Hail, Saudi Arabia. E-mail: ammarqta2002@,hotmail.com

Academic Editor: Alessandro Leite Cavalcanti

Received: 25 May 2020 / Review: 15 June 2020 / Accepted: 24 June 2020

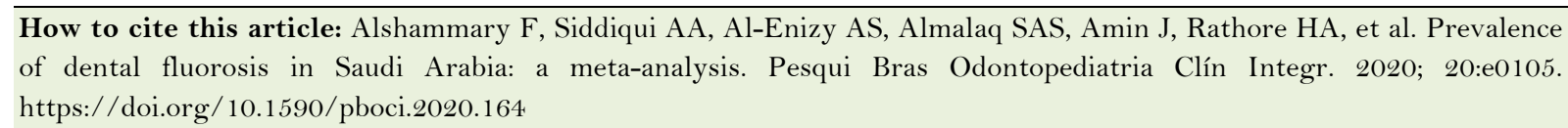
https://doi.org/10.1590/pboci.2020.164

\begin{abstract}
Objective: To identify the prevalence of dental fluorosis in Kingdom of Saudi Arabia. Material and Methods: Literature search for the present study aimed to include all the relevant studies conducted in Saudi Arabia that reported prevalence of dental fluorosis. A literature search was done using keywords (dental, fluorosis, prevalence) using three databases (Scopus, PubMed, and Web of Science). Grey literature was also searched using Google Scholar and research gate. Literature was searched from 1939 till April 2020. The risk of bias was reported using JBI Critical Appraisal Checklist for Studies Reporting Prevalence Data. Twelve studies were included based on inclusive criteria. The only inclusive criteria were studies that were conducted among people living in Saudi Arabia, and studies that reported the prevalence of dental fluorosis. Samples from all age groups that reported prevalence of dental fluorosis were included. MedCalc statistical software was used to perform the analysis. Results: The overall prevalence of dental fluorosis was found to be $46.52 \%$, $95 \mathrm{CI}(26.52 \%$ to $67.12 \%)$. I2 value was reported $99.8 \%$, 95 CI $(99.78 \%$ to $99.83 \%)$, indicating high heterogeneity amongst the finding of studies. Funnel plots indicate the presence of a strong publication bias. Overall, we found some contrasting findings. One study reported prevalence of dental fluorosis as $\mathrm{O} \%$ and other with a comparatively large sample size found dental fluorosis to be $90.6 \%$. Conclusion: The present study adds to the literature regarding dental fluorosis in Saudi Arabia by providing an overview of its prevalence. It is concluded that prevalence of dental fluorosis was a bit high. However, findings indicate publication bias. We did not account for severity of dental fluorosis. All the available data was analyzed to measure dental fluorosis prevalence without considering the sample size and sampling technique.
\end{abstract}

Keywords: Fluorosis, Dental; Epidemiology; Prevalence; Study Characteristics. 


\section{Introduction}

Dental fluorosis is quite abundant in various populations around the globe. For certain geographical regions, mostly the hilly areas, it is quite common and considered as a substantial dental public health problem [1]. It is a development disorder that occurs during the stage of tooth formation because of excessive fluoride exposure. It decreases the mineral content of dental enamel by creating porosity [2], which in return can brittle the enamel surface, making it susceptible to break.

There are other related risk factors for dental fluorosis, such as consumption of diet rich in fluoride, which can be termed under individual susceptibility; besides, renal insufficiency is also associated with dental fluorosis [3]. One of the most significant complications linked with excessive fluoride is esthetic changes to dental enamel. It is quite common among children highly exposed to extreme fluoride levels during 2-3 years of age [4]. Interestingly, it seems that dental fluorosis in on the raise not only in area rich in fluoride but also in many non-fluoridated regions [5].

As per available data from various studies conducted in Kingdom from 1997 onwards, it can be said that dental fluorosis is amply present in Saudi Arabian population. Numerous studies reported prevalence of dental fluorosis in Saudi Arabia differently at separate times in the same region. It was noticed that dental fluorosis prevalence varies greatly at various times and in several regions [6].

However, to our best knowledge till date, there exists no study, which provides an estimate of prevalence of dental fluorosis in Kingdom in terms of proportion. The present study was planned to answer this question. This meta-analysis will provide the first of its kind of study in Kingdom population, which will provide valuable data for policymakers to made guidelines concerns to controlling dental fluorosis in Saudi Arabia.

\section{Material and Methods}

Search Strategy

The studies used in this meta-analysis were searched through keywords that include "Prevalence", and "Dental Fluorosis". Primarily, three databases were explored: Scopus, Pub Med and Web of Science. Gray literature was searched manually through Google scholar rand, research gate. The search was also done by looking at the references of relevant studies. The search strategy used for the present study includes MESH terms such as dental fluorosis, prevalence, severity, OR/AND prevalence, dental fluorosis, severity, OR/AND dental fluorosis, severity, prevalence.

\section{Selection of Studies and Extraction of Data}

The total number of studies found from 1939-2020 using the above stated keywords were 3747.In Scopus $(n=1101)$ were identified, PubMed $(n=1316)$ and in Web of Science $(n=1325)$. Manual searching resulted in 5 more studies. The Reference Management Software Package (Endnote X9) was used to remove duplicated studies and assess titles and abstracts of the remaining studies. The total number of studies after duplicated studies removed was 1850 .

Two reviewers evaluated all articles according to "JBI Critical Appraisal Checklist for Studies Reporting Prevalence Data”. Data extracted from eligible studies include information on the proportion of dental fluorosis reported, sample size, the method used to measure dental fluorosis, year of study and region/city where the study was performed, and the authors reported age group. Differences in reporting were referred to a third reviewer. Only articles in English that addressed the prevalence of dental fluorosis in Saudi 
Arabia were included. Studies that were conducted outside Saudi Arabia $(n=1821)$ and studies that had irrelevant titles $(\mathrm{n}=10)$ were excluded. The remaining 19 studies' full-text and abstracts were reviewed, the articles that did not mention the prevalence of dental fluorosis were excluded. Those four studies were excluded due to reporting and detection bias, while one study due to lack of full-text access and two review studies were also excluded. Finally, a sample of 12 articles that were selected for meta-analysis that was fulfilling the "JBI Critical Appraisal Checklist for Studies Reporting Prevalence Data" and relevant to our study objective i.e., to report the prevalence of dental fluorosis in Saudi Arabia (Figure 1).

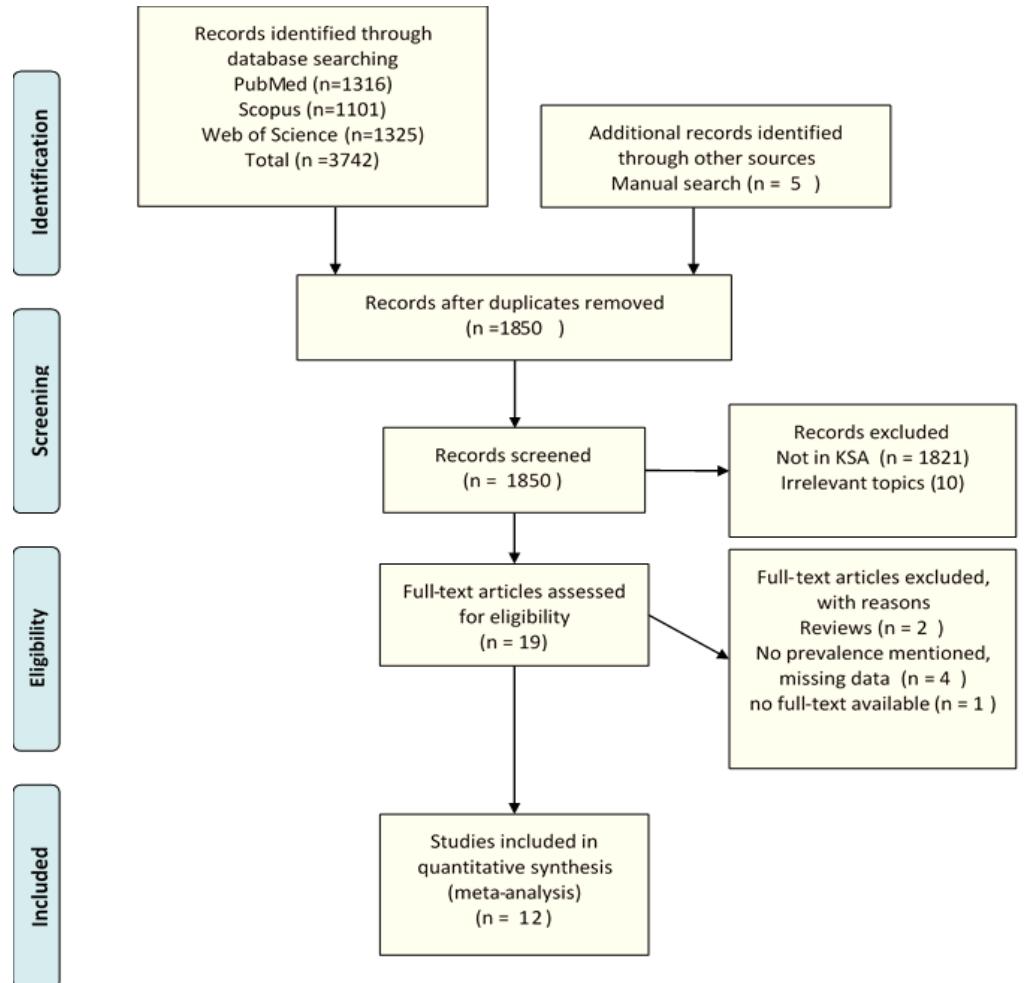

Figure 1. Flow chart for selection of studies.

Quality Appraisal and Data Synthesis

Two independent reviewers assessed the risk of bias in the included studies using Joanna Briggs Institute (JBI) Critical Appraisal Checklist for Prevalence Studies [7]. This checklist included 9 items; it can be answered by (Yes), (No), (Unclear) or (Not Applicable). Yes will be scored as (1), both (No) and (Unclear) will be scored (0), and (Not Applicable) will exclude the item from the checklist for that study. Studies were categorized as follow: 1) High risk of bias if only 40-60\% of the checklist questions were answered with (Yes); 2) Moderate risk of bias if $60-80 \%$ of the checklist questions were answered with (Yes); and 3) Low risk of bias if $80-100 \%$ of the checklist questions were answered with (Yes).

The most apparent limitation that increased the risk of bias noticed in the included studies was the setting details (were the study subjects and the setting described in detail).

The proportion of dental fluorosis prevalence was calculated with the appropriate $95 \%$ confidence interval (CI), and MedCalc statistical software was used to perform the meta-analysis. Heterogeneity was reported using $I^{2}$ statistics. High heterogeneity amongst the studies used in this meta-analysis was found $99.80 \%, 95$ CI $(99.78 \%$ to $99.83 \%)$. In this case random effect model is more appropriate; however, data was displayed as a random effect model as well as a fixed-effect model. 


\section{Results}

This meta-analysis includes data from 12 studies [8-19] from 11 regions of Saudi Arabia (Table 1). We did not find any study in remaining two areas of the country. The earliest study included in this analysis was conducted during 1997 and the most recent was planned in 2020. Few studies that reported severity of dental fluorosis or did not clearly mentioned the prevalence of dental fluorosis were excluded as it was beyond the scope of the present meta-analysis. There is more than one index for measuring dental fluorosis; not all the included studies have used the same study tool whilst reporting dental fluorosis that can slightly misrepresent the overall reported prevalence. A total sample size of 14,573 subjects was included in this study that was derived from 12 different studies conducted on prevalence of dental fluorosis in Saudi Arabia.

Table 1. The characteristics of the included studies.

\begin{tabular}{lcccccc}
\hline \multicolumn{1}{c}{ Authors } & Year & $\begin{array}{c}\text { Age Group } \\
\text { (Years) }\end{array}$ & Region & $\begin{array}{c}\text { Index } \\
\text { Sample }\end{array}$ & $\begin{array}{c}\text { Prevalence } \\
\text { Size (n) DT (n) }\end{array}$ \\
\hline Akpata et al. [8] & 1997 & $12-15$ & Hail & TFI & 2,355 & 2,135 \\
Al-Shammery et al. [9] & 1997 & $6-7,12-13,15-74$ & Multiple Regions\# & DI & 7,377 & 1,815 \\
Almas et al. [10] & 1999 & $12,15,35-44,>65$ & Al-Qaseem & DI & 800 & 339 \\
Al-Banyan et al. [11] & 2000 & $5-12$ & Riyadh & CFI & 272 & 38 \\
Khan et al. [12] & 2001 & $24-44$ & Riyadh & DI & 297 & 224 \\
Bhayat et al. [13] & 2014 & 12 & Al-Madinah & DI & 360 & 0 \\
Khan et al. [14] & 2014 & $6-12$ & Dammam & DI & 496 & 164 \\
Alhobeira et al. [15] & 2015 & $10-20,20-30,30-40,>40$ & Hail & DI & 253 & 186 \\
Alanazi et al. [16] & 2017 & $7-15$ & Riyadh & NIM & 157 & 39 \\
Elsherbini et al. [17] & 2018 & $6-12$ & Al-Qassim & DI & 1,292 & 832 \\
Elfaki et al. [18] & 2018 & $6-12$ & Najran & DI & 288 & 172 \\
Haridi et al. [19] & 2020 & $7-12$ & Hail & DI & 626 & 484 \\
\hline
\end{tabular}

\#Eastern Province, Al-Qassim, Hail, Tabouk, Najran, Al Baha, Gizan, Makkah, Al-Madinah and Asir; DF: Dental Fluorosis; DI: Dean Index; NIM: No Index Mentioned; TFI: Thylstrup-Fejerskov Index; CFI: The Community Fluorosis Index.

The selected studies were classified according to regions (Figure 2). There were three studies, each from Riyadh and Hail regions constituted (25\%) of included studies. Two studies were from Al- Qassim (17\%). One study was found in each of the following three regions, Dammam (8\%), Al-Madinah (8\%) and Najran (8\%). One study was conducted including 10 regions: Eastern Province, Qassim, Hail, Tabouk, Najran, Al Baha, Gizan, Makkah, AlMadinah and Asir.

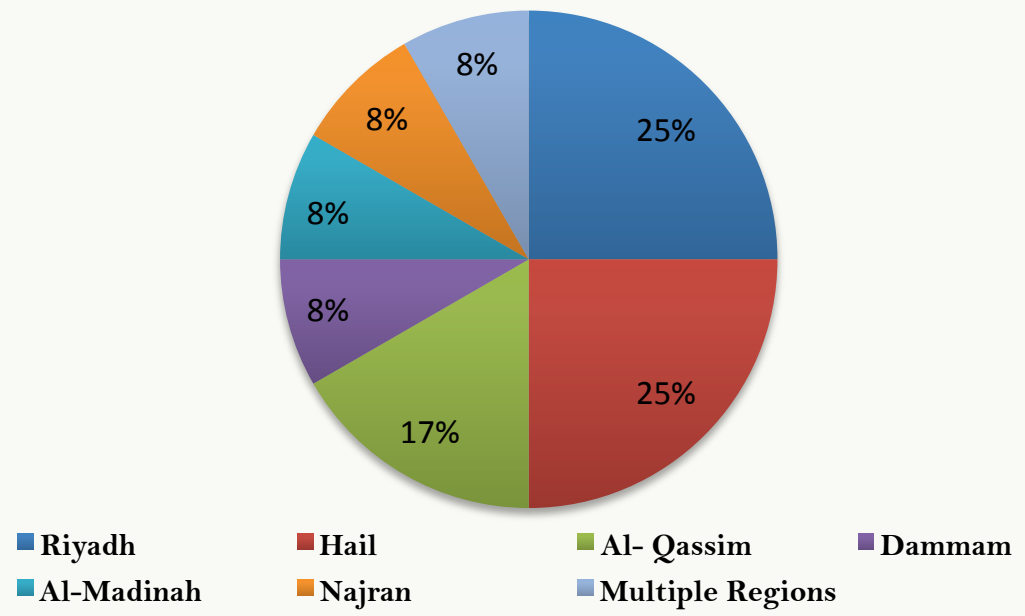

Figure 2. The distribution of studies reporting prevalence of dental fluorosis region-wise in Saudi Arabia. 
Summary statistics in terms of proportion at $95 \%$ CI can be seen in Table 2 . The estimated prevalence of dental fluorosis in terms of proportion (random effect model) was found to be $46.52 \%$ (95\% CI: 26.52-67.12). Interestingly, one study has reported $0 \%$ dental fluorosis, which may influence the overall reported proportion. Cochran's $Q$ value alongside p-value is reported in Table 1, indicating high heterogeneity, as shown in I 2 value 99.80 (95\% CI: 99.78 to 99.83 ) (Table 2 ).

Table 2. Summary of studies and variables included after inclusive criteria year-wise (chronological pattern) and reported prevalence of dental fluorosis in Saudi Arabia.

\begin{tabular}{|c|c|c|c|c|c|}
\hline \multirow[t]{2}{*}{ Studies } & \multirow[t]{2}{*}{ Sample Size } & \multirow[t]{2}{*}{ Proportion (\%) } & \multirow[t]{2}{*}{$95 \% \mathrm{CI}$} & \multicolumn{2}{|c|}{ Weight (\%) } \\
\hline & & & & Fixed & Random \\
\hline Akpata et al. [8] & 2355 & 90.658 & 89.410 to 91.804 & 16.15 & 8.36 \\
\hline Al-Shammery et al. [9] & 7377 & 24.603 & 23.624 to 25.603 & 50.59 & 8.37 \\
\hline Almas et al. [10] & 800 & 42.375 & 38.922 to 45.885 & 5.49 & 8.35 \\
\hline Al-Banyan et al. [ $\left[\begin{array}{ll}1 & 1\end{array}\right]$ & 297 & 75.421 & 70.116 to 80.211 & 2.04 & 8.32 \\
\hline Khan et al. [12] & 272 & 13.971 & 10.080 to 18.668 & 1.87 & 8.32 \\
\hline Bhayat et al. [13] & 360 & 0.000 & 0.000 to 1.019 & 2.48 & 8.33 \\
\hline Khan et al. [14] & 496 & 33.065 & 28.935 to 37.397 & 3.41 & 8.34 \\
\hline Alhobeira et al. [15] & 253 & 73.518 & 67.627 to 78.848 & 1.74 & 8.31 \\
\hline Alanazi et al. [16] & 157 & 24.841 & 18.299 to 32.357 & 1.08 & 8.28 \\
\hline Elsherbini et al. [17] & 1292 & 64.396 & 61.716 to 67.011 & 8.87 & 8.36 \\
\hline Elfaki et al. [18] & 288 & 59.722 & 53.808 to 65.434 & 1.98 & 8.32 \\
\hline Haridi et al. [19] & 626 & 77.316 & 73.831 to 80.541 & 4.30 & 8.35 \\
\hline Total (Fixed Effects) & 14573 & 43.981 & 43.173 to 44.791 & 100.00 & 100.00 \\
\hline Total (Random Effects) & 14573 & 46.523 & 26.522 to 67.127 & 100.00 & 100.00 \\
\hline
\end{tabular}

Q Statistics $=5605.53 ;$ DF 1 1, I2 (Inconsistency) $=99.80 \%(99.78$ to 99.83 at $95 \%) ; \mathrm{p}<0.00$.

Forest played showing the proportion prevalence of dental fluorosis of each study. It can be seen that the highest prevalence was reported by a study by Akpata et al. [8], whereas the lowest was reported by Bhayat et al. [13]. As I2 value was found to be more than 75, which indicates the presence of high heterogeneity, hence random effects model is suggested to use. However mean proportion from both models, random and fixed, is displayed in Figure 3.

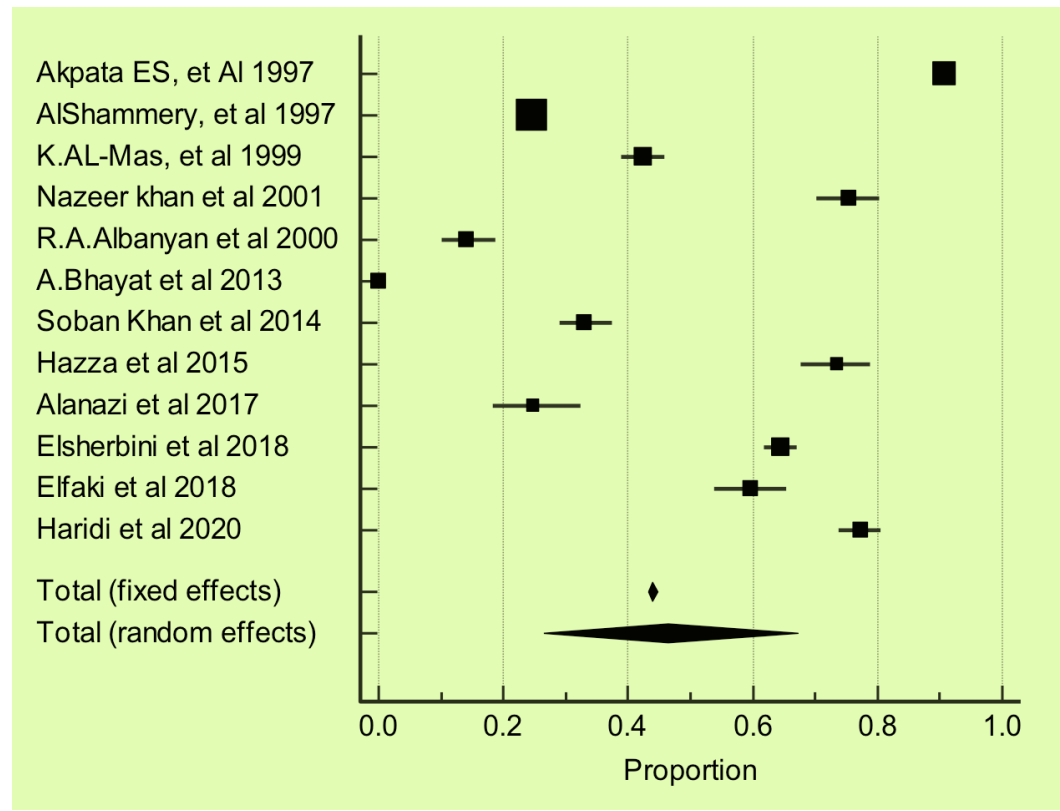

Figure 3. Study dispersion and possible publication bias. 
Visual inspection of funnel plot indicates that it's asymmetrical, which can be due to the possibility of substantial publication bias, presence of poor methodological design (Figure 4).

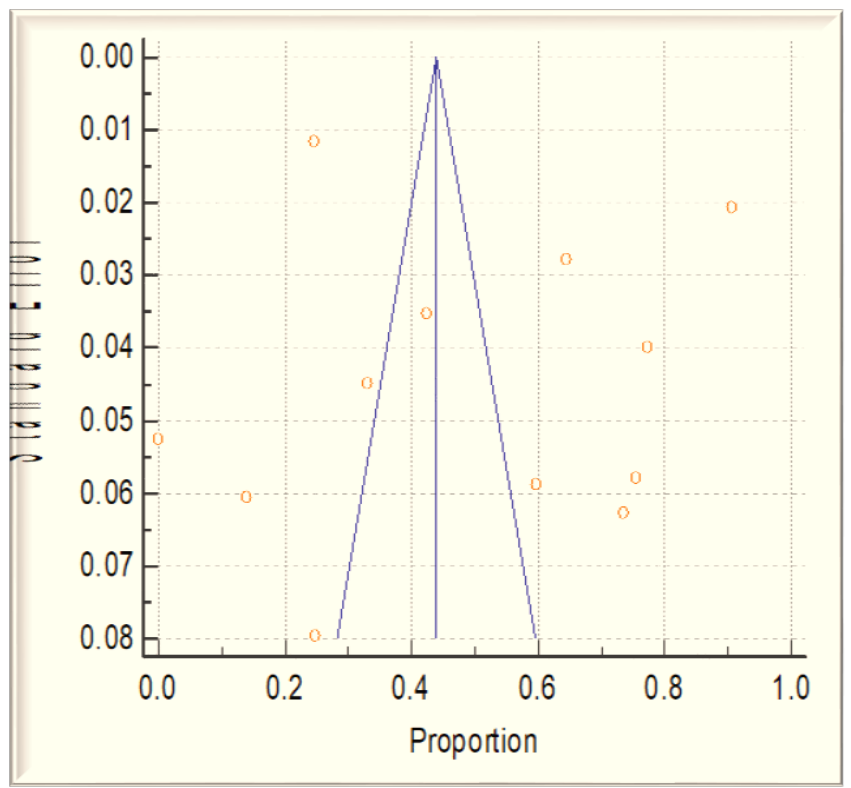

Figure 4. Funnel plot-showing prevalence of dental fluorosis as proportion from 1997-2020.

Approximately half $(50 \%)$ of the studies either did not mention the setting at all, or they only mentioned it briefly and without enough details. Most of the studies had overall good quality. Out of the twelve studies that have been included, eight were considered to have a low risk of bias and three studies with a moderate risk of bias. Only one study that had a high risk of bias; in this study, the sample size was inadequate, and the authors did not mention what methodology they have used for scoring fluorosis (Figures 5 and 6).



\section{.Low Risk of Bias .High Risk of Bias}

Figure 5. Items of JBI Critical Appraisal Checklist of included studies. 


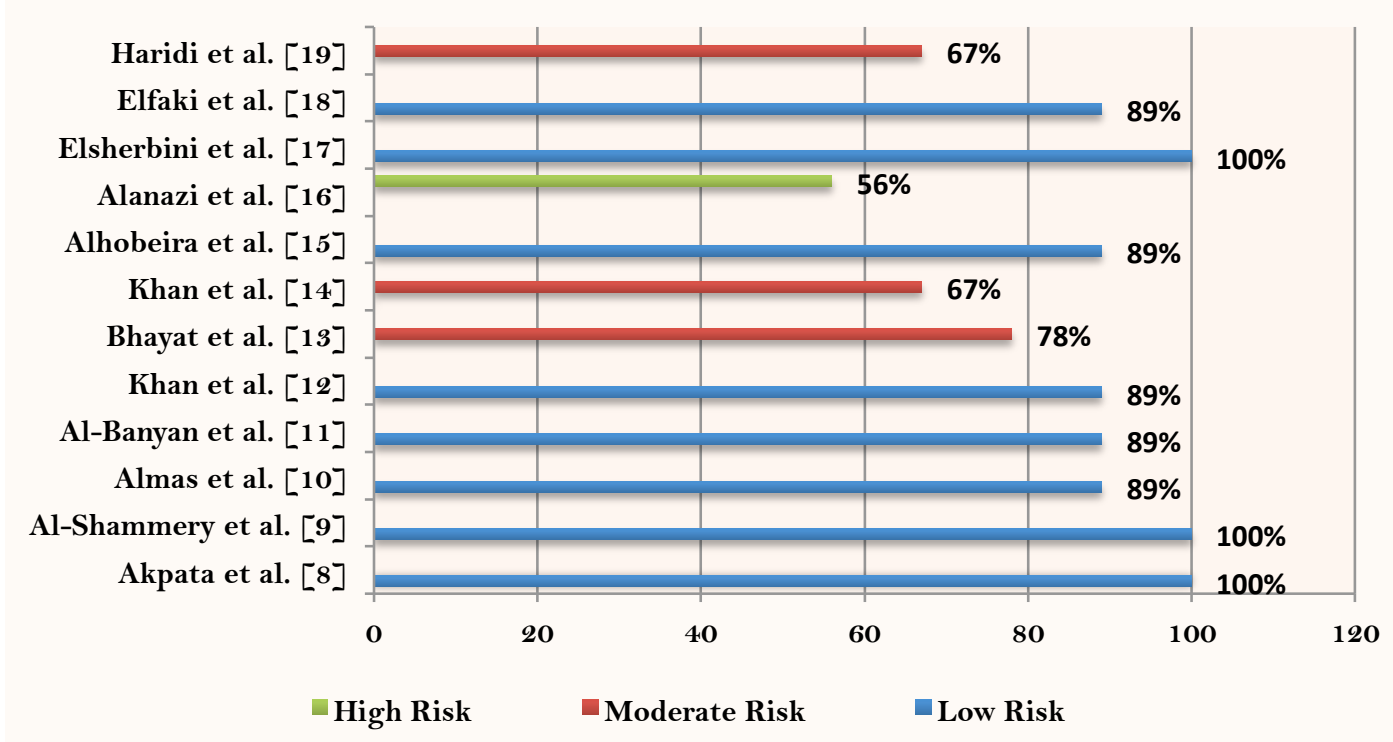

Figure 6. Risk of bias assessment scores of included studies

\section{Discussion}

The present study aimed to provide an estimate of prevalence of dental fluorosis in Saudi Arabia in terms of proportion. The present meta-analysis includes all the studies that were conducted in Saudi Arabia that have reported prevalence of dental fluorosis, without considering age, gender, or presence of high level of fluoride in drinking water. In this study, a total sample of 14573 subjects was considered from 12 different studies and overall prevalence of dental fluorosis was $46.52 \%$, $95 \mathrm{CI}(26.52 \%$ to $67.12 \%)$. I2 value was reported $99.80 \%$, 95 CI (99.78\% to $99.83 \%)$. Visual inspection of funnel plot indicates that it's asymmetrical, which can be due to the possibility of substantial publication bias, presence of poor methodological design. However, a visual inspection can be used to provide a very subjective picture. Another probable reason for asymmetry is the presence of studies with a smaller sample size. Other probable reasons for bias may involve the language bias, reporting of studies available in English language only, and citation bias where studies with more positive outcomes are cited more and can be easily identified in databases. Besides that, a bias can be evolved because of selected reporting of favorable results by authors (Figure 4).

These findings are in line with a study conducted in South Africa that reported 47\% [20], and a study from Ethiopia reported $45.3 \%$ of dental fluorosis [21]. The findings of present study differ from a study conducted in 2007 on German schoolchildren [22] and a study from India reported $11.3 \%$ and $4 \%$ prevalence of dental fluorosis [23].

Three studies were included from Riyadh city $[11,12,16]$. Khan at al. conducted a study among participants aged 30 to above 40 years with a sample size of 297 participants and reported a very mild to moderate dental fluorosis among them, and the overall prevalence was 75\% [12]. Al-Banyan et al. conducted a study among children aged 5-12 years among 272 participants and mild dental fluorosis was reported, but an overall prevalence of $14 \%$ was reported by them [11]. Alanazi at al. conducted among 7 to 15 years of age children $(\mathrm{n}=157)$ and reported an overall 25\% dental fluorosis among the participants [16]. The findings from all the three studies in Riyadh were different from each other in reporting the prevalence of dental fluorosis even in the same city. Thus, this difference indicates the need of this meta-analysis to answer or make an estimate of dental fluorosis in Saudi Arabia. 
There were three studies conducted in Hail $[8,15,19]$. Akpatta et al. included 12 to 15 years of age children $(\mathrm{n}=2355)$ and reported $91 \%$ of overall prevalence of dental fluorosis constituted the highest reported prevalence among any city of Saudi Arabia [8]. Another study conducted by Alhobeira et al. included 253 participants and reported mild to moderate fluorosis with $73.5 \%$ of overall prevalence [15]. The most recent study conducted by Haridi et al. reported the overall prevalence of $77.32 \%$ dental fluorosis with a sample size of 626 participants [19]. Two studies were almost in line with the study conducted by Khan et al. in Riyadh [12]. Dental fluorosis was found to be abundant in Hail region, probably because of a high fluoride concentration in the drinking water. However, findings from the aforementioned studies conducted in Hail region reported a very high prevalence $(91 \%, 73.5 \%$, and $77.32 \%)$, which is contrasting with the prevalence reported from this meta-analysis $(46.52 \%)$. The variation in prevalence of dental fluorosis could be because of various reasons, that include but not limited to exposure to well water, which contains a high level of fluoride, as mentioned by a study reported from Hail region [15]. Other probable reasons may be related to weather, altitude of the area from where sample was collected, exposure to an artificial source of fluoride at an early stage or could be because of availability of high level of fluoride in infant milk prescribed by the physicians [6].

Based on a single study conducted in Al Qassim province reported 42.37\% overall prevalence among 600 participants of aged 12-65 years. The study reported a $24-67 \%$ prevalence of dental fluorosis among age groups of 12-15, 34-45 and above 65 years. Sixty-seven (67\%) of respondents between 34-45 years had severe dental fluorosis [10]. These findings are very much in line with the result of this meta-analysis. Likewise, a single study conducted in Al Madinah reported a $0 \%$ prevalence of dental fluorosis among 360 participants [13]. This is the only study that did not report any prevalence of dental fluorosis in Saudi Arabia. According to the author, the possible reason for this might be the drinking of bottled water by the sampled population. In contrast, the study from Hail had reported mild to moderate dental fluorosis while primarily drinking bottled water among respondents. These contradicting findings are directing to explore the prevalence of dental fluorosis in Saudi population in relation to the use of formula milk during infancy as the presence of fluoride in formula milk can be a potential risk of dental caries [24,25].

A single study conducted in Dammam included 496 participants reported a $33.1 \%$ prevalence of dental fluorosis [14]. Another study conducted in Najran on 288 participants reported a $59.72 \%$ prevalence of dental fluorosis [18]. Whilst the survey conducted in Al Raas on 1292 participants reported a 64.1\% prevalence of dental fluorosis [17]. The findings from the above-mentioned studies are within the 95CI of the present metaanalysis.

Previous authors conducted a population-based study that included more than 7000 participants from large cities of all regions of Saudi Arabia [9]. The overall prevalence of dental fluorosis was 24.6\%, but the region based prevalence was not reported that can contribute to respondent bias in the study. In their research, they also found the variation of dental fluorosis in numerous age groups. The highest prevalence, $38 \%$, was in 20-29 years, while the lowest prevalence, 8\%, was in children aged 5-6 years. The high prevalence of dental fluorosis is highlighted to measure the fluoride concentration in the drinking water. Moreover, a significant difference was established among the respondents of urban and rural areas that are further directing to explore the underlying risk factors.

We did not account for severity of dental fluorosis. All the available data was analyzed to measure dental fluorosis prevalence without considering the sample size and sampling technique. We did not find any studies from 2 regions of Saudi Arabia. Most of the data was reported from urban regions of the country. The real picture can be a bit different then what is reported in this meta-analysis. 


\section{Conclusion}

The present study adds to the literature regarding dental fluorosis in Saudi Arabia by providing an overview of its prevalence. It is concluded that the prevalence of dental fluorosis was a bit high. Only one study was found to be inconsistent with overall reported proportion, while three were within the $95 \% \mathrm{CI}$ range of reported prevalence. However, findings indicate publication bias.

\section{Authors' Contributions}

\begin{tabular}{|c|c|c|}
\hline ASF & (D) $0000-0002-1850-9273$ & $\begin{array}{l}\text { Conceptualization, Methodology, Formal Analysis, Writing - Original Draft } \\
\text { Preparation and Writing - Review and Editing. }\end{array}$ \\
\hline SAA & (D) $0000-0002-8816-6421$ & $\begin{array}{l}\text { Conceptualization, Methodology, Investigation, Formal Analysis, Writing - } \\
\text { Original Draft Preparation and Writing. }\end{array}$ \\
\hline ESA & (D) $0000-0002-3603-9332$ & $\begin{array}{l}\text { Methodology, Formal Analysis, Writing - Original Draft Preparation and Writing } \\
\text { - Review and Editing. }\end{array}$ \\
\hline ASAS & (D) $0000-0002-8036-1417$ & Writing - Original Draft Preparation and Writing - Review and Editing. \\
\hline AJ & (1D) $0000-0002-4343-2255$ & $\begin{array}{l}\text { Formal Analysis, Writing - Original Draft Preparation and Writing - Review and } \\
\text { Editing. }\end{array}$ \\
\hline RHA & (D) $0000-0002-1154-9395$ & $\begin{array}{l}\text { Formal Analysis, Writing - Original Draft Preparation and Writing - Review and } \\
\text { Editing. }\end{array}$ \\
\hline $\mathrm{SF}$ & (D) $0000-0002-1798-5876$ & Writing - Original Draft Preparation and Writing - Review and Editing. \\
\hline MKA & (D) $0000-0001-7131-1752$ & $\begin{array}{l}\text { Formal Analysis, Writing - Original Draft Preparation and Writing - Review and } \\
\text { Editing. }\end{array}$ \\
\hline
\end{tabular}

\section{Financial Support}

None.

\section{Conflict of Interest}

The authors declare no conflicts of interest.

\section{References}

[1] Petersen, PE. The world oral health report 2003: continuous improvement of oral health in the 21 st century-the approach of the WHO Global Oral Health Programme. Community Dent Oral Epidemiol 2003; 31(Suppl 1):3-23. https://doi.org/10.1046/j..2003.com122.x

[2] Alvarez JA, Rezende KMPC, Marocho SMS, Alves FBT, Celiberti P, Ciamponi AL. Dental fluorosis: exposure, prevention and management. Med Oral Patol Oral Cir Bucal 2009; 14(2):E103-7.

[3] Akosu TJ, Zoakah AI. Risk factors associated with dental fluorosis in Central Plateau State, Nigeria. Community Dent Oral Epidemiol 2008; 36(2):144-8. https://doi.org/10.1111/j.1600-0528.2007.00387.x

[4] Rodrigues CRMD, Ramires Romito ACD, Zardetto CGDC. Abordagem Educativa-Preventiva em Odontopediatria. In: Cardoso RJA, Gonçalves EAN. Odontopediatria: Prevenção.. São Paulo: Artes Médicas; 2002. [In Portuguese]

[5] Clark DC. Trends in prevalence of dental fluorosis in North America. Community Dent Oral Epidemiol 1994; 22(3):148-52. https://doi.org/10.1111/j.1600-0528.1994.tbo1832.x

[6] Siddiqui AA, Al Hobeira H, Mirza AJ, Alshammari AK, Alshammari BA, Alsalwah NF. Dental fluorosis in Saudi Arabia: A review of current literature. Ann Int Med Dent Res 2017; 3(3):44-9. https://doi.org/10.21276/aimdr.2017.3.3.DE10

[7] Munn Z, Moola S, Lisy K, Riitano D, Tufanaru C. Methodological guidance for systematic reviews of observational epidemiological studies reporting prevalence and cumulative incidence data. Int J Evid Based Healthc 2015; 13(3):147-53. https://doi.org/10.1097/xeb.0000000000000054

[8] Akpata ES, Fakiha Z, Khan N. Dental fluorosis in 12-15-year-old rural children exposed to fluorides from well drinking water in the Hail region of Saudi Arabia. Community Dent Oral Epidemiol 1997; 25(4):324-7. https://doi.org/10.1111/j.1600-0528.1997.tbo0947.x

[9] Al-Shammery AR, Guile EE, El Backly M. The prevalence of dental fluorosis in Saudi Arabia. Saudi Dental Journal 1997; 9(2):58-61. 
[10] Almas K, Shakir ZF, Afzal M. Prevalence and severity of dental fluorosis in Al-Qaseem province - Kingdom of Saudi Arabia. Odontostomatol Trop 1999; 22(85):44-7.

[11] Al-Banyan RA, Echeverri EA, Narendran S, Keene HJ. Oral health survey of 5-12-year-old children of National Guard employees in Riyadh, Saudi Arabia. Int J Paediatr Dent 2000; 10(1):39-45. https://doi.org/10.1046/j.1365-263x.2000.00166.x

[12] Khan N, Al-Zarea B, Al-Mansour MJSDJ. Dental caries, hygiene, fluorosis and oral health knowledge of primary school teachers of Riyadh, Saudi Arabia. Saudi Dent J 2001; 13(3):128-32.

[13] Bhayat A, Ahmad MS. Oral health status of 12-year-old male schoolchildren in Medina, Saudi Arabia. Eastern Mediterr Health J 2014; $20(11): 732-7$.

[14] Khan SQ, Moheet IA, Farooq I, Farooqi FA, ArRejaie AS, Al Abbad MHA, et al. Prevalence of dental fluorosis in school going children of Dammam, Saudi Arabia. J Dent Allied Sci 2015; 4(2):69-72. https://doi.org/10.4103/2277-4696.171516

[15] Alhobeira HA, Siddiqui AA, Mian RI. Prevalence and severity of dental fluorosis in Hail, Saudi Arabia. J Int Oral Health $2015 ; 7(12): 1-4$.

[16] Alanazi AH, Alsaab FA, Alatallah SS, Alfahaid SF, Alharbi AS, Almutairi BS, et al. Fluoride level in drinking water and prevalence of dental fluorosis and dental caries among the school children: A descriptive cross-sectional study. Asian Pac J Health Sci 2017; 4(4):155-9. https://doi.org/10.2 1276/apjhs.2017.4.4.35

[17] Elsherbini MS, Alsughier Z, Elmoazen RA, Habibullah MA. Prevalence and severity of dental fluorosis among primary school children in AlRass, Saudi Arabia. Int J Med Health Res 2018; 4(3):45-9.

[18] Elfaki NK, Elsheikh AS, Assiry AA, Alsunbul F. Dental fluorosis prevails among primary-schools' students in Najran City-Saudi Arabia. Merit Res J Med Med Sci 2018; 6(3):121-5.

[19] Haridi HK, Alshammary BA, Albaqawi FH, Alshammry MM, Alhumaid ME, Alhur RS, et al. Prevalence and severity of dental fluorosis among school children aged 7-12 years in Hail City, Saudi Arabia. EC Dental Science 2020; $19(2): 1-6$.

[20] Grobler SR, Louw AJ, van Kotze TJ. Dental fluorosis and caries experience in relation to three different drinking water fluoride levels in South Africa. Int J Paediatr Dent 2001; 11(5):372-9. https://doi.org/10.1046/j.0960-7439.2001.00293.x

[21] Wondwossen F, Åstrøm AN, Bjorvatn K, Bårdsen A. The relationship between dental caries and dental fluorosis in areas with moderate and high fluoride drinking water in Ethiopia. Community Dent Oral Epidemiol 2004; 32(5):33744. https://doi.org/10.1111/j.1600-0528.2004.00172.x

[22] Momeni A, Neuhäuser A, Renner N, Heinzel-Gutenbrunner M, Abou-Fidah J, Rasch K, et al. Prevalence of dental fluorosis in German schoolchildren in areas with different preventive programmes. Caries Res 2007; 41(6):437-44. https://doi.org/10.1159/000107929

[23] Chauhan D, Chauhan T, Sachdev V, Kirtaniya BC. A study of prevalence and severity of dental fluorosis among school children in a Northern hilly state of India. SRM J Res Dent Sci 2012; 3(3):170-4. https://doi.org/10.4103/0976-433X.107395

[24] Fomon SJ, Ekstrand J, Ziegler EE. Fluoride intake and prevalence of dental fluorosis: trends in fluoride intake with special attention to infants: Review \& commentary. J Public Health Dent 2000; 60(3):131-9. https://doi.org/10.1111/j.1752-7325.2000.tbo3318.x

[25] Osujp OO, Leake JL, Chipman ML, Nikiforuk G, Locker D, Levine N. Risk factors for dental fluorosis in a fluoridated community. J Dent Res 1988; 67(12):1488-92. https://doi.org/10.1177/00220345880670120901 